\title{
Thermophysical properties of uranium-europium mixed oxides
}

\author{
R. VENKATA KRISHNAN, R. BABU, Abhiram SENAPATI, \\ G. JOGESWARARAO, K. ANANTHASIVAN* \\ Fuel Chemistry Division, Indira Gandhi Centre for Atomic Research, Kalpakkam-603102, Tamil Nadu, India
}

Received: April 16, 2015; Revised: May 12, 2015; Accepted: May 18, 2015

(C) The Author(s) 2015. This article is published with open access at Springerlink.com

\begin{abstract}
Uranium-europium mixed oxides $\left(\mathrm{U}_{1-y} \mathrm{Eu}_{y}\right) \mathrm{O}_{2-x}(y=0.2-0.8)$ were prepared by the citrate gel combustion technique and characterized by X-ray diffraction (XRD). Single phase fluorite structure was observed in those solid solutions with $y \leqslant 0.6$. The solid solutions with $y>0.6$ were found to be biphasic, with the second phase being cubic $\mathrm{Eu}_{2} \mathrm{O}_{3}$. Heat capacity and enthalpy increment measurements were carried out by using differential scanning calorimeter (DSC) and drop calorimeter in the temperature range $298-800 \mathrm{~K}$ and $800-1800 \mathrm{~K}$, respectively. The $C_{p, m}$ values at $298 \mathrm{~K}$ for $\left(\mathrm{U}_{1-y} \mathrm{Eu}_{y}\right) \mathrm{O}_{2-x}(y=0.2,0.4,0.6)$ are $64.8,64.6$, and $63.5 \mathrm{~J} \cdot \mathrm{K}^{-1} \cdot \mathrm{mol}^{-1}$, respectively. An anomalous increase was observed in the heat capacity in all of the solid solutions with the onset temperature around $950 \mathrm{~K}$. This could be attributed to the contribution from Frenkel pair oxygen defects. From the excess heat capacity data, the enthalpy for the formation of these defects was computed and found to be in the range of $2.10 \pm 0.02 \mathrm{eV}$.
\end{abstract}

Keywords: uranium; europium; solid solution; calorimetry; heat capacity; Frenkel defects

\section{Introduction}

Solid solution of uranium-plutonium mixed oxides is used as a driver fuel in fast reactors. Fission products formed during the irradiation of the fuel are found within its matrix as metallic inclusions, oxide precipitates, and oxide solid solutions. Hence, the composition and the physiochemical properties of the fuel get significantly altered [1-3]. Thermal induced transport phenomena and chemical interactions among these constituents further accelerate the changes. The thermal conductivity and heat capacity of these solid solutions are important to understand the in-pile behaviour of the fuel. Among the fission products, the rare earths form a sizable fraction (fission yield 50 at $\%$ )

* Corresponding author.

E-mail: asivan@igcar.gov.in
[4]. Owing to their ionic radii (in their oxides) that are comparable with those of fuel constituents ( $\mathrm{U}$ and $\mathrm{Pu}$ ), the rare earths are significantly soluble in the mixed oxide fuel matrix [5]. The studies on the solid solubility of $\mathrm{EuO}_{1.5}$ in $\mathrm{UO}_{2}$, oxygen potentials of uraniumeuropium solid solutions, as well as their defect chemistry, have been reported in the literature [5-9]. Heat capacity data on uranium-europium mixed oxides with europium content of 4.4 and $9.0 \mathrm{~mol} \%$ have been reported by Matsui et al. [10]. These authors have observed anomalous increase in the heat capacity, which sets in at temperatures ranging from 950 to $1150 \mathrm{~K}$. Such an anomalous increase in the heat capacity observed in $\mathrm{UO}_{2}$ doped with rare earth oxides $\left(\mathrm{REO}_{1.5}, \mathrm{RE}=\mathrm{La}, \mathrm{Gd}, \mathrm{Nd}\right)$ has been reported in our earlier works [11-13]. Matsui et al. [10] reported the heat capacity measured by using direct heating pulse calorimetry in the temperature range $300-1550 \mathrm{~K}$ for 
$\left(\mathrm{U}_{1-y} \mathrm{Eu}_{y}\right) \mathrm{O}_{2-x}(y=0.044-0.09)$. In the present work, the heat capacity and enthalpy increment measurements of $\left(\mathrm{U}_{1-y} \mathrm{Eu}_{y}\right) \mathrm{O}_{2-x}$ were carried out over a wide range of composition $(y=0.2-0.8)$. These results are discussed in this paper.

\section{Experimental}

\section{1 Sample preparation and characterization}

Europium oxide of $99.99 \%$ purity supplied by M/s. Indian Rare Earths and nuclear grade uranium oxide supplied by NFC, Hyderabad, were used for preparing the samples. The solid solutions $\left(\mathrm{U}_{1-y} \mathrm{Eu}_{y}\right) \mathrm{O}_{2-x}(y=$ $0.2-0.8$ ) were prepared by citrate gel combustion synthesis. The procedure using which these samples were prepared was reported in our earlier publication [12]. These sample pellets were reduced by heating them in a stream of $\mathrm{Ar}+8 \% \mathrm{H}_{2}$ gas mixture at $873 \mathrm{~K}$. Subsequently these pellets were sintered at $1873 \mathrm{~K}$ for $6 \mathrm{~h}$. A heating/cooling rate was maintained $200 \mathrm{~K} \cdot \mathrm{h}^{-1}$. Before heating the samples, the furnace was evacuated $\left(10^{-3}\right.$ mbar $)$ and filled with ultra high pure $\mathrm{Ar}+8 \% \mathrm{H}_{2}$ gas mixture thrice. The concentrations of $\mathrm{U}$ and $\mathrm{Eu}$ in the sintered sample pellets were determined by inductively coupled plasma atomic emission spectroscopy (ICP-AES). The concentrations of other metallic impurities were determined by inductively coupled plasma mass spectrometer (ICP-MS) (model number ELAN 250 of M/s. Perkn Helmer, Canada). The samples were analyzed for carbon impurity by using carbon analyzer (model number ELTRACS 800 of M/s. Eltra, Germany). Structural characterization was carried out by using X-ray diffraction (XRD). The XRD patterns were recorded in the range $10^{\circ}<2 \theta<80^{\circ}$. Peak positions and their relative intensities were computed by using a peak-fit program, which was part of the Philips X'pert Plus ${ }^{\circledR}$ software. The calibration of the diffractometer was carried out by using single crystal silicon and $\alpha$-alumina standards. The lattice parameter pertaining to the solid solution samples was estimated from the $2 \theta$ values pertaining to eight major reflections of the oxide with $\mathrm{CaF}_{2}$ structure. Finally an effective high angle corrected lattice parameter at each temperature was obtained by the standard Nelson Riley extrapolation procedure.

\section{2 Calorimetric measurements}

A heat flux type differential scanning calorimeter (DSC, model number DSC821e/700 of M/s. Mettler Toledo $\mathrm{GmbH}$, Switzerland) was used in this study. Temperature, heat flow, heat flow rate, and $\tau$-lag calibrations were carried out, as explained in our previous publications $[11,14,15]$. The uncertainty in the heat capacity data measured by the DSC was estimated to be about $2 \%-3 \%$ based on our previous measurements on standard $\mathrm{ThO}_{2}$ samples [15]. The enthalpy increments of these samples in the temperature range $800-1800 \mathrm{~K}$ were determined by using a high temperature drop calorimeter equipped with multi-detector (MHTC-96) supplied by M/s. SETARAM. The procedures used in the measurement of heat capacity and enthalpy increment are described elsewhere [11-15].

\section{Results and discussion}

\section{1 Chemical assay and phase characterization}

The results of the impurity analysis carried out by using ICP-MS and carbon analyzer are listed in Table 1. The total concentration of impurities in all these solid solutions is found to be less than $500 \mathrm{ppm}$. The results of the chemical assay (concentrations of $U$ and $\mathrm{Eu}$ ) by ICP-AES shown in Table 2 are in good agreement within $\pm 1 \%$ of the expected values. The room temperature XRD patterns pertaining to $\left(\mathrm{U}_{1-y} \mathrm{Eu}_{y}\right) \mathrm{O}_{2-x}$ $(y=0.2-0.8)$ are shown in Fig. 1. It is evident from this figure that the solid solutions $\left(\mathrm{U}_{1-y} \mathrm{Eu}_{y}\right) \mathrm{O}_{2-x} \quad(y=$ 0.2-0.65) show a single phase fluorite structure, whereas in the XRD patterns pertaining to samples with $y$ values greater than 0.65 , additional peaks pertaining to the cubic $\mathrm{Eu}_{2} \mathrm{O}_{3}$ phase [16] are observed. However, scanning electron microscopy-energy dispersive X-ray analysis (SEM-EDAX) of $\left(\mathrm{U}_{0.35} \mathrm{Eu}_{0.65}\right) \mathrm{O}_{2-x}$ confirms the precipitation of the cubic $\mathrm{Eu}_{2} \mathrm{O}_{3}$ phase. The results of the EDAX analysis of $\left(\mathrm{U}_{1-y} \mathrm{Eu}_{y}\right) \mathrm{O}_{2-x}(y=0.2,0.4,0.6$, $0.65)$ are shown in Fig. 2. In the SEM analysis of the solid solutions, $\left(\mathrm{U}_{1-y} \mathrm{Eu}_{y}\right) \mathrm{O}_{2-x}$ pertaining up to the value of $y$ equal to 0.6 , only cuboidal (plate) like microstructures are formed. However, for $\left(\mathrm{U}_{0.35} \mathrm{Eu}_{0.65}\right) \mathrm{O}_{2-x}$ in addition to cuboidal crystallites, acicular (rod) like microstructures are also found. EDAX analysis on various positions of the pellets of $\left(\mathrm{U}_{1-y} \mathrm{Eu}_{y}\right) \mathrm{O}_{2-x} \quad(y=0.2, \quad 0.4, \quad 0.6)$ shows uniform composition pertaining to that of solid solution confirming the phase homogeneity throughout the pellet. However, for $\left(\mathrm{U}_{0.35} \mathrm{Eu}_{0.65}\right) \mathrm{O}_{2-x}$, the EDAX analysis (Fig. 
Table 1 Concentrations of impurities in U-Eu mixed oxides using ICP-MS

\begin{tabular}{cccc}
\hline \multirow{2}{*}{ Element } & \multicolumn{3}{c}{ Concentration of impurity $(\mathrm{ppm})$} \\
\cline { 2 - 4 } & $\left(\mathrm{U}_{0.8} \mathrm{Eu}_{0.2}\right) \mathrm{O}_{2-x}$ & $\left(\mathrm{U}_{0.6} \mathrm{Eu}_{0.4}\right) \mathrm{O}_{2-x}$ & $\left(\mathrm{U}_{0.4} \mathrm{Eu}_{0.6}\right) \mathrm{O}_{2-x}$ \\
\hline $\mathrm{Ni}$ & 10 & 9 & 5 \\
$\mathrm{Zn}$ & 5 & 6 & 3 \\
$\mathrm{Mo}$ & 14 & 10 & 7 \\
$\mathrm{Ba}$ & $<1$ & $<1$ & $<1$ \\
$\mathrm{Al}$ & $<1$ & $<1$ & 2 \\
$\mathrm{Mg}$ & $<1$ & $<1$ & $<1$ \\
$\mathrm{Ca}$ & $<1$ & 8 & 3 \\
$\mathrm{~V}$ & $<1$ & $<1$ & $<1$ \\
$\mathrm{Cr}$ & 16 & 9 & 8 \\
$\mathrm{Mn}$ & 6 & 1 & 2 \\
$\mathrm{Fe}$ & 56 & 45 & 54 \\
$\mathrm{Cu}$ & $<1$ & $<1$ & 2 \\
$\mathrm{Ce}$ & 14 & 4 & 8 \\
$\mathrm{La}$ & $<1$ & 6 & 14 \\
$\mathrm{Sm}$ & $<1$ & $<1$ & 1 \\
$\mathrm{Nd}$ & $<1$ & $<1$ & $<1$ \\
$\mathrm{Gd}$ & 18 & 28 & 31 \\
$\mathrm{Dy}$ & $<1$ & $<1$ & $<1$ \\
$\mathrm{C}$ & $<100$ & $<100$ & $<100$ \\
\hline
\end{tabular}

Table 2 Relative concentrations of $U$ and $E u$ determined by ICP-AES

\begin{tabular}{ccc}
\hline Solid solution & $\mathrm{U}(\mathrm{mol} \%)$ & $\mathrm{Eu}(\mathrm{mol} \%)$ \\
\hline$\left(\mathrm{U}_{0.8} \mathrm{Eu}_{0.2}\right) \mathrm{O}_{2-x}$ & 79.9 & 20.1 \\
$\left(\mathrm{U}_{0.6} \mathrm{Eu}_{0.4}\right) \mathrm{O}_{2-x}$ & 60.2 & 39.8 \\
$\left(\mathrm{U}_{0.4} \mathrm{Eu}_{0.6}\right) \mathrm{O}_{2-x}$ & 39.9 & 60.1 \\
$\left(\mathrm{U}_{0.35} \mathrm{Eu}_{0.65}\right) \mathrm{O}_{2-x}$ & 35.2 & 64.8 \\
$\left(\mathrm{U}_{0.3} \mathrm{Eu}_{0.7}\right) \mathrm{O}_{2-x}$ & 30.1 & 69.9 \\
$\left(\mathrm{U}_{0.25} \mathrm{Eu}_{0.75}\right) \mathrm{O}_{2-x}$ & 24.9 & 75.1 \\
$\left(\mathrm{U}_{0.2} \mathrm{Eu}_{0.8}\right) \mathrm{O}_{2-x}$ & 19.9 & 80.1 \\
\hline
\end{tabular}

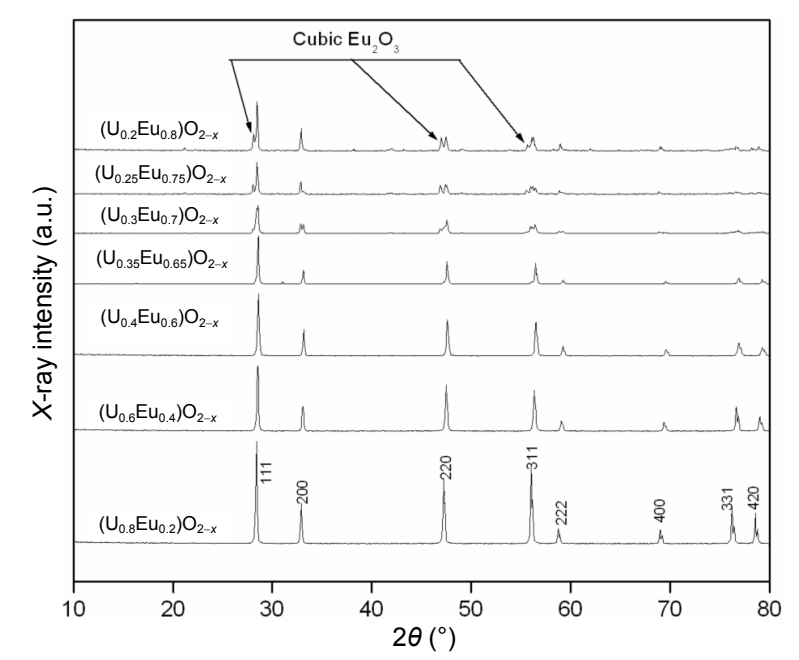

Fig. 1 Room temperature XRD patterns of $\left(\mathrm{U}_{1-y} \mathrm{Eu}_{y}\right) \mathrm{O}_{2-x}$ $(y=0.2-0.8)$.

2) on cuboidal crystallites shows peaks pertaining to $U$, $\mathrm{Eu}$, and $\mathrm{O}$ (composition pertaining to solid solution), whereas that on acicular crystallites shows peaks pertaining to only Eu and $\mathrm{O}$. The lattice parameter of
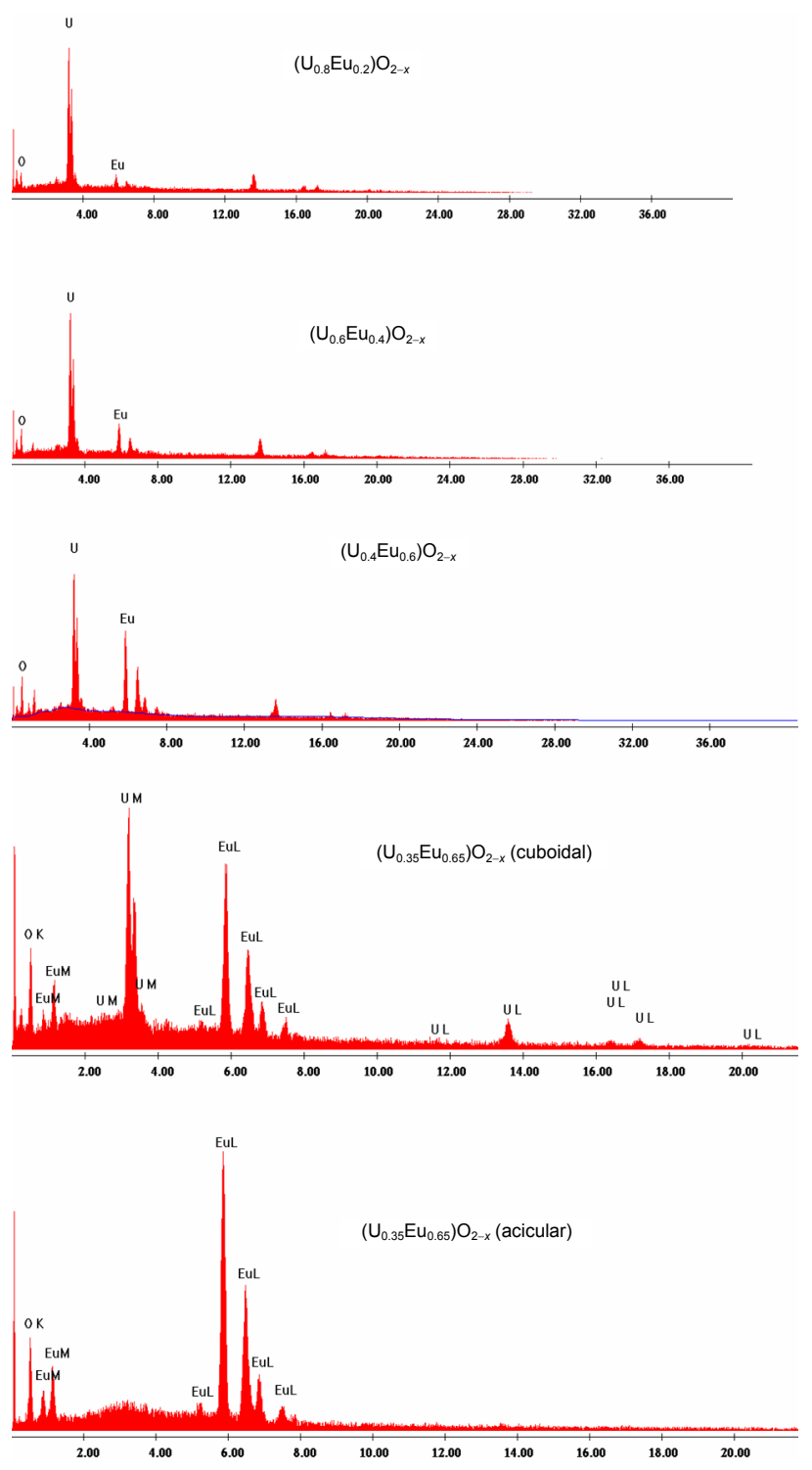

Fig. 2 Results of EDAX analysis of $\left(\mathrm{U}_{1-y} \mathrm{Eu}_{y}\right) \mathrm{O}_{2-x}$ $(y=0.2,0.4,0.6,0.65)$.

$\left(\mathrm{U}_{1-y} \mathrm{Eu}_{y}\right) \mathrm{O}_{2-x} \quad(y=0.2,0.4,0.6)$ decreases with the Eu content of the solid solution and the values of lattice parameters are $0.5451,0.5437$, and $0.5425 \mathrm{~nm}$, respectively. Upon increasing the concentration of Eu in these solid solutions, no change is observed in their lattice parameters. Therefore, it is evident that the terminal solid solubility of $\mathrm{EuO}_{1.5}$ in $\mathrm{UO}_{2}$ is in the range of $60-65 \mathrm{~mol} \%$. The heat capacity and enthalpy increment measurements were carried out only on the single phase solid solutions $\left(\mathrm{U}_{1-y} \mathrm{Eu}_{y}\right) \mathrm{O}_{2-x}(y=0.2,0.4$, $0.6)$.

\section{2 Calorimetric measurements}

The measured values of the enthalpy increment in the 
temperature range $800-1800 \mathrm{~K}$ were fitted into a four-term polynomial function represented below (by least squares regression analysis):

$$
H_{T}-H_{298}=A T+B \times 10^{-3} T^{2}+C \times 10^{5} T^{-1}+D \times 10^{4}
$$

where $A, B$, and $C$ are the coefficients obtained from the polynomial fit. The constraints used for this fit are (i) $H_{T}-H_{298}=0$ at $298 \mathrm{~K}$ and (ii) the temperature derivative of the function at $298 \mathrm{~K}$ is equal to $C_{p, 298}$ (measured by using DSC). The coefficients of those polynomials pertaining to the solid solutions $\left(\mathrm{U}_{1-y} \mathrm{Eu}_{y}\right) \mathrm{O}_{2-x}(y=0.2,0.4,0.6)$ are presented in Table 3. The plot of temperature dependence of the enthalpy increment corresponding to $\left(\mathrm{U}_{1-y} \mathrm{Eu}_{y}\right) \mathrm{O}_{2-x}(y=0.2,0.4$, $0.6)$ are presented in Fig. 3.

The values of the heat capacity measured by using DSC and those computed from the enthalpy increment by using drop calorimeter were fitted into a polynomial through a least squares regression analysis. The expressions for the temperature dependence of heat capacity values corresponding to the solid solutions $\left(\mathrm{U}_{1-y} \mathrm{Eu}_{y}\right) \mathrm{O}_{2-x}(y=0.2,0.4,0.6)$ are presented in Table 4. From these heat capacity data, the enthalpy, entropy,

Table 3 Coefficients in the function obtained by least squares regression analysis $(800 \mathrm{~K} \leqslant T \leqslant 1800 \mathrm{~K})$ for $\left(\mathrm{U}_{1-y} \mathbf{E u}_{y}\right) \mathbf{O}_{2-x}$

\begin{tabular}{cccc}
\hline Coefficient & $\left(\mathrm{U}_{0.8} \mathrm{Eu}_{0.2}\right) \mathrm{O}_{2-x}\left(\mathrm{U}_{0.6} \mathrm{Eu}_{0.4}\right) \mathrm{O}_{2-x}\left(\mathrm{U}_{0.4} \mathrm{Eu}_{0.6}\right) \mathrm{O}_{2-x}$ \\
\hline$A$ & 80.1 & 77.9 & 75.5 \\
$B$ & 1.35 & 1.34 & 1.63 \\
$C$ & 1.39 & 1.20 & 1.10 \\
$D$ & -2.87 & -2.74 & -2.64 \\
Standard error $\left(\mathrm{J} \cdot \mathrm{mol}^{-1}\right)$ & 14 & 15 & 80 \\
\hline
\end{tabular}

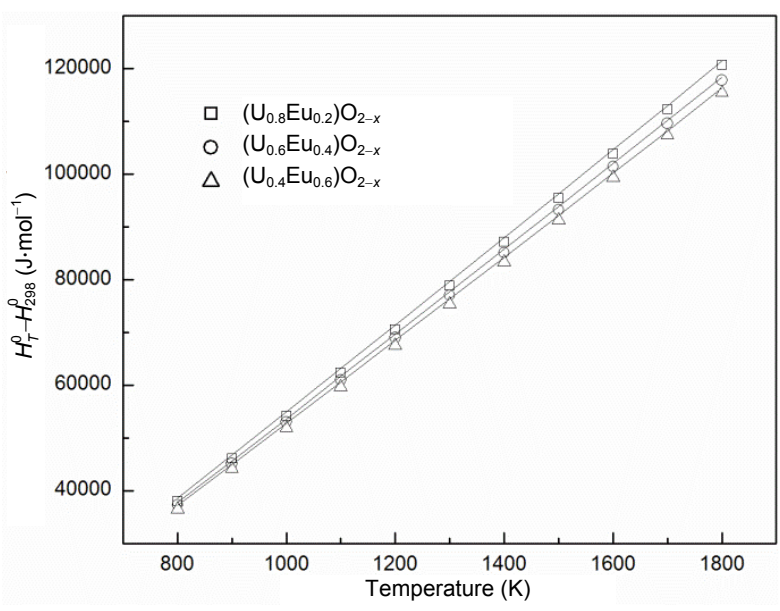

Fig. 3 Enthalpy increment of $\left(\mathrm{U}_{1-y} \mathrm{Eu}_{y}\right) \mathrm{O}_{2-x}$ from drop calorimetry. and Gibbs energy functions were computed. These results are presented in Tables 5-7. The values of $S_{298}$ pertaining to $\left(\mathrm{U}_{1-y} \mathrm{Eu}_{\mathrm{y}}\right) \mathrm{O}_{2-x}$, required for the computation of $S_{T}$ were estimated by using Neumann-Kopp's approximation by using the values of $S_{298}^{0}$ of $\mathrm{Eu}_{2} \mathrm{O}_{3}$ [17] and $\mathrm{UO}_{2}$ [18].

The combined fit of the heat capacity of $\left(\mathrm{U}_{1-y} \mathrm{Eu}_{y}\right) \mathrm{O}_{2-x}$ $(y=0.2,0.4,0.6)$ obtained from the DSC and drop calorimetric experiments is shown in Fig. 4. As seen in the figure, the heat capacity values of $\left(\mathrm{U}_{1-y} \mathrm{Eu}_{y}\right) \mathrm{O}_{2-x}(y=$ $0.2,0.4,0.6)$ decrease with an increase in the Eu content of the solid solution. The dependence of phonon frequencies on the reduced mass of an oscillator comprising masses $m_{1}$ and $m_{2}$ is given in Eqs. (2) and (3).

Table 4 Expressions obtained by least squares regression analysis for the temperature dependence of heat capacity $(298 \mathrm{~K} \leqslant T \leqslant 1800 \mathrm{~K})$ for $\left(\mathrm{U}_{1-y} \mathrm{Eu}_{y}\right) \mathrm{O}_{2-x}$

\begin{tabular}{ccc}
\hline Compound & Fit equation $\left(\mathrm{J} \cdot \mathrm{K}^{-1} \cdot \mathrm{mol}^{-1}\right)$ & $\begin{array}{c}\text { Standard error } \\
\left(\mathrm{J} \cdot \mathrm{K}^{-1} \cdot \mathrm{mol}^{-1}\right)\end{array}$ \\
\hline$\left(\mathrm{U}_{0.8} \mathrm{Eu}_{0.2}\right) \mathrm{O}_{2-x}$ & $\begin{array}{c}87.51-6.79 \times 10^{-3} T-1.877632 \times \\
10^{6} T^{-2}+3.0739 \times 10^{-6} T^{2}\end{array}$ & 1.02 \\
& $84.40-5.84 \times 10^{-3} T-1.631278 \times$ \\
$\left(\mathrm{U}_{0.6} \mathrm{Eu}_{0.4}\right) \mathrm{O}_{2-x}$ & $10^{6} T^{-2}+2.7889 \times 10^{-6} T^{2}$ \\
& $85.00-9.39 \times 10^{-3} T-1.696035 \times$ \\
$\left(\mathrm{U}_{0.4} \mathrm{Eu}_{0.6}\right) \mathrm{O}_{2-x}$ & $10^{6} T^{-2}+4.226 \times 10^{-6} T^{2}$ & 0.84 \\
\hline
\end{tabular}

Table 5 Thermodynamic functions pertaining to $\left(\mathbf{U}_{0.8} \mathbf{E u}_{0.2}\right) \mathbf{O}_{2-x}$

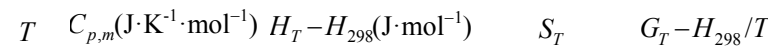

(K) $\overline{\text { Measured Fit }}$ Measured Fit $\left(\mathrm{J} \cdot \mathrm{K}^{-1} \cdot \mathrm{mol}^{-1}\right)\left(\mathrm{J} \cdot \mathrm{K}^{-1} \cdot \mathrm{mol}^{-1}\right)$

$\begin{array}{llllll}298 & 64.77 & 64.62 & 0 & 88.9 & -88.9\end{array}$

$\begin{array}{llllll}300 & 65.02 & 64.89 & 130 & 89.3 & -88.9\end{array}$

$\begin{array}{llllll}400 & 73.24 & 73.55 & 7116 & 109.4 & -91.6\end{array}$

$\begin{array}{llllll}500 & 77.48 & 77.37 & 14685 & 126.2 & -96.9\end{array}$

$\begin{array}{llllll}600 & 80.16 & 79.33 & 22530 & 140.5 & -103.0\end{array}$

$\begin{array}{llllll}700 & 82.09 & 80.43 & 30523 & 152.9 & -109.2\end{array}$

$\begin{array}{lllllll}800 & 83.64 & 81.11 & 38029 & 38602 & 163.6 & -115.4\end{array}$

$\begin{array}{lllllll}900 & 81.57 & 46078 & 46738 & 173.2 & -121.3\end{array}$

$\begin{array}{lllllll}1000 & 81.92 & 54192 & 54913 & 181.8 & -126.9\end{array}$

$\begin{array}{llllll}1100 & 82.21 & 62361 & 63119 & 189.7 & -132.3\end{array}$

$\begin{array}{lllllll}1200 & 82.48 & 70578 & 71354 & 196.8 & -137.4\end{array}$

$\begin{array}{lllllll}1300 & 82.77 & 78838 & 79616 & 203.4 & -142.2\end{array}$

$\begin{array}{lllllll}1400 & 83.07 & 87138 & 87908 & 209.6 & -146.8\end{array}$

$\begin{array}{llllll}1500 & 83.41 & 95475 & 96231 & 215.3 & -151.2\end{array}$

$\begin{array}{lllllll}1600 & 83.78 & 103847 & 104590 & 220.7 & -155.3\end{array}$

$\begin{array}{llllll}1700 & 84.20 & 112253 & 112989 & 225.8 & -159.3\end{array}$

\begin{tabular}{lllllll}
1800 & 84.67 & 120691 & 121432 & 230.6 & -163.2 \\
\hline
\end{tabular} 
Table 6 Thermodynamic functions pertaining to $\left(\mathbf{U}_{\mathbf{0 . 6}} \mathbf{E u}_{\mathbf{0 . 4}}\right) \mathbf{O}_{2-x}$

\begin{tabular}{|c|c|c|c|c|c|c|}
\hline \multirow{2}{*}{$\begin{array}{c}T \\
(\mathrm{~K})\end{array}$} & \multicolumn{2}{|c|}{$C_{p, m}\left(\mathrm{~J} \cdot \mathrm{K}^{-1} \cdot \mathrm{mol}^{-1}\right)$} & \multicolumn{2}{|c|}{$H_{T}-H_{298}\left(\mathrm{~J} \cdot \mathrm{mol}^{-1}\right)$} & \multirow{2}{*}{$\begin{array}{c}S_{T} \\
\left(\mathrm{~J} \cdot \mathrm{K}^{-1} \cdot \mathrm{mol}^{-1}\right)\end{array}$} & \multirow{2}{*}{$\begin{array}{r}G_{T}-H_{298} / T \\
\left(\mathrm{~J} \cdot \mathrm{K}^{-1} \cdot \mathrm{mol}^{-1}\right)\end{array}$} \\
\hline & Measured & Fit & Measured & Fit & & \\
\hline 298 & 64.64 & 64.54 & & 0 & 81.7 & -81.7 \\
\hline 300 & 64.85 & 64.78 & & 129 & 82.1 & -81.7 \\
\hline 400 & 72.12 & 72.32 & & 7040 & 102.0 & -84.4 \\
\hline 500 & 75.81 & 75.65 & & 14459 & 118.5 & -89.6 \\
\hline 600 & 78.10 & 77.37 & & 22119 & 132.5 & -95.6 \\
\hline 700 & 79.72 & 78.35 & & 29909 & 144.5 & -101.8 \\
\hline 800 & 80.99 & 78.97 & 37281 & 37777 & 155.0 & -107.8 \\
\hline 900 & & 79.39 & 45126 & 45696 & 164.3 & -113.5 \\
\hline 1000 & & 79.72 & 53032 & 53652 & 172.7 & -119.0 \\
\hline 1100 & & 80.01 & 60988 & 61639 & 180.3 & -124.3 \\
\hline 1200 & & 80.28 & 68989 & 69653 & 187.3 & -129.2 \\
\hline 1300 & & 80.56 & 77031 & 77695 & 193.7 & -134.0 \\
\hline 1400 & & 80.86 & 85111 & 85765 & 199.7 & -138.4 \\
\hline 1500 & & 81.19 & 93226 & 93868 & 205.3 & -142.7 \\
\hline 1600 & & 81.56 & 101375 & 102005 & 210.5 & -146.8 \\
\hline 1700 & & 81.97 & 109557 & 110181 & 215.5 & -150.7 \\
\hline 1800 & & 82.42 & 117770 & 118401 & 220.2 & -154.4 \\
\hline
\end{tabular}

Table 7 Thermodynamic functions pertaining to $\left(\mathbf{U}_{0.4} \mathbf{E u}_{0.6}\right) \mathbf{O}_{2-x}$

\begin{tabular}{|c|c|c|c|c|c|c|}
\hline \multirow{2}{*}{$\begin{array}{c}T \\
(\mathrm{~K})\end{array}$} & \multicolumn{2}{|c|}{$C_{p, m}\left(\mathrm{~J} \cdot \mathrm{K}^{-1} \cdot \mathrm{mol}^{-1}\right)$} & \multicolumn{2}{|c|}{$H_{T}-H_{298}\left(\mathrm{~J} \cdot \mathrm{mol}^{-1}\right)$} & \multirow{2}{*}{$\mathrm{C}_{\left(\mathrm{J} \cdot \mathrm{K}^{-1} \cdot \mathrm{mol}^{-1}\right)}$} & \multirow{2}{*}{$\begin{array}{c}G_{T}-H_{298} / T \\
\left(\mathrm{~J} \cdot \mathrm{K}^{-1} \cdot \mathrm{mol}^{-1}\right)\end{array}$} \\
\hline & Measured & Fit & Measured & Fit & & \\
\hline 298 & 63.48 & 63.48 & & 0 & 76.0 & -76.0 \\
\hline 300 & 63.70 & 63.72 & & 127 & 76.4 & -76.0 \\
\hline 400 & 71.25 & 71.32 & & 6937 & 95.9 & -78.6 \\
\hline 500 & 74.99 & 74.57 & & 14252 & 112.2 & -83.7 \\
\hline 600 & 77.23 & 76.17 & & 21798 & 126.0 & -89.7 \\
\hline 700 & 78.77 & 77.03 & & 29462 & 137.8 & -95.7 \\
\hline 800 & 79.93 & 77.54 & 36467 & 37193 & 148.1 & -101.6 \\
\hline 900 & & 77.87 & 44140 & 44965 & 157.3 & -107.3 \\
\hline 1000 & & 78.14 & 51877 & 52766 & 165.5 & -112.7 \\
\hline 1100 & & 78.38 & 59668 & 60591 & 173.0 & -117.9 \\
\hline 1200 & & 78.64 & 67509 & 68442 & 179.8 & -122.8 \\
\hline 1300 & & 78.93 & 75395 & 76320 & 186.1 & -127.4 \\
\hline 1400 & & 79.27 & 83324 & 84229 & 192.0 & -131.8 \\
\hline 1500 & & 79.67 & 91294 & 92176 & 197.4 & -136.0 \\
\hline 1600 & & 80.13 & 99302 & 100165 & 202.6 & -140.0 \\
\hline 1700 & & 80.66 & 107349 & 108204 & 207.5 & -143.8 \\
\hline 1800 & & 81.26 & 115432 & 116299 & 212.1 & -147.5 \\
\hline
\end{tabular}

$$
\begin{gathered}
v=\frac{1}{2 \pi}(k / \mu) \\
\mu=\frac{m_{1} \cdot m_{2}}{m_{1}+m_{2}}
\end{gathered}
$$

where $v$ is the phonon frequency; $k$ is the force constant; and $\mu$ is the reduced mass. The atomic weight of $U$ is 238.03 while that of $E u$ is 151.97. Doping of $E u$ in $\mathrm{UO}_{2}$ lattice will lead to a decrease in the reduced mass. The lower the reduced mass, the higher would be the phonon frequency. The higher the phonon frequency, the lower would be the heat capacity. The increase in the phonon frequency due to the above mentioned factor contributes to the decrease in the heat capacity of $\left(\mathrm{U}_{1-y} \mathrm{Eu}_{y}\right) \mathrm{O}_{2-x}$ with an increase in the concentration of $\mathrm{Eu}$.

From Fig. 4, it is evident that considerable anomalous increase in the heat capacity is found to set in at onset temperatures ranging from 950 to $1000 \mathrm{~K}$ in all these solid solutions. Such anomalous increase in the heat capacity is usually observed when $\mathrm{UO}_{2}$ is doped with an aliovalent cation (in this case $\mathrm{Eu}^{+3}, \mathrm{Eu}^{+2}$ ). This phenomenon was reported earlier [11-13,19-25] and has been ascribed to the formation of oxygen Frenkel defect pairs. An estimate of the temperature dependence of the heat capacity pertaining to the solid solutions $\left(\mathrm{U}_{1-y} \mathrm{Eu}_{y}\right) \mathrm{O}_{2-x}(y=0.2,0.4,0.6)$ over the temperature range $298-1800 \mathrm{~K}$ was obtained by extrapolating the expression derived through the least squares regression analysis of these data in the temperature range 298$900 \mathrm{~K}$. This would hence forth be termed as baseline heat capacity. The baseline $(298-900 \mathrm{~K})$ and the combined experimentally determined temperature dependence of heat capacity data in the temperature range $298-1800 \mathrm{~K}$ were fitted to the following polynomials by least squares regression analysis, respectively:

$$
\begin{gathered}
C_{p}(\text { baseline })=A+B T+C T^{-2} \\
C_{p}(\text { experimental })=A+B T+C T^{-2}+D T^{2}
\end{gathered}
$$

The temperature dependence of the heat capacity values (baseline and combined experimental values) is shown in Fig. 4. The difference between these values of the heat capacity is termed as the excess heat capacity $\left(\Delta C_{p}\right)[10-13]$. The temperature dependence of this

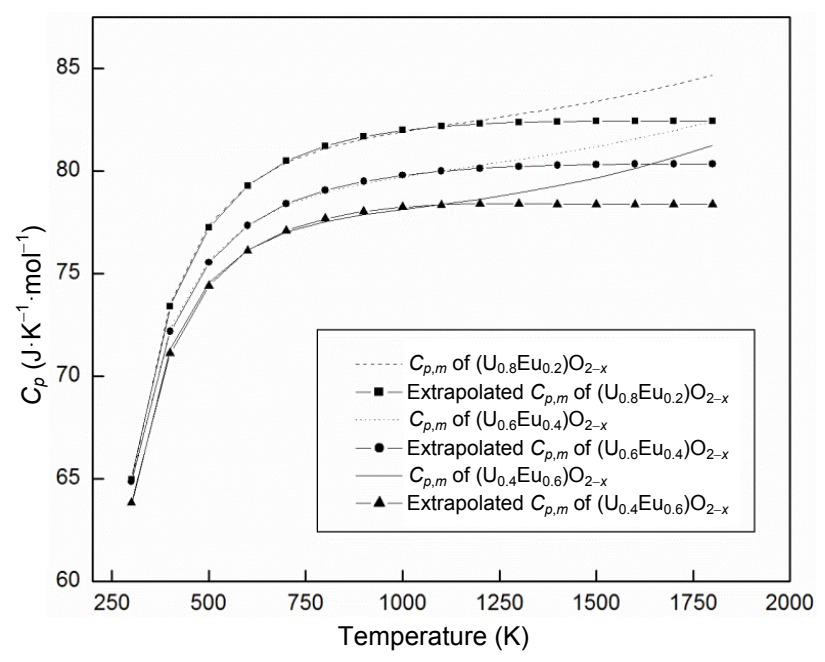

Fig. 4 Temperature dependent heat capacity data of $\left(\mathrm{U}_{1-y} \mathrm{Eu}_{y}\right) \mathrm{O}_{2-x}(y=0.2,0.4,0.6)$. 
excess heat capacity is shown in Fig. 5. It is evident from this figure that the onset temperature of heat capacity anomaly is around $950 \mathrm{~K}$ for all of the solid solutions $\left(\mathrm{U}_{1-y} \mathrm{Eu}_{y}\right) \mathrm{O}_{2-x}$. Matsui et al. [10] measured the heat capacities of $\left(\mathrm{U}_{1-y} \mathrm{Eu}_{y}\right) \mathrm{O}_{2} \quad(y=0.044-0.09)$ and have observed that the temperature at which the anomalous increase in the heat capacity sets in gets lowered with an increase in the concentration of Eu in the solid solution. These authors attributed this phenomenon to the decrease in the enthalpy of the formation of defects $\left(\Delta H_{\mathrm{d}}\right)$ with an increase in the dopant concentration. However, it is seen in our earlier work on $\left(\mathrm{U}_{1-y} \mathrm{Gd}_{y}\right) \mathrm{O}_{2 \pm x}[13]$ and $\left(\mathrm{U}_{1-y} \mathrm{La}_{y}\right) \mathrm{O}_{2 \pm x}[11]$ that the onset temperature of the heat capacity anomaly as well as the enthalpy for the formation of defects do not decrease continuously with increase in the dopant (aliovalent cation) concentration. The onset temperature of heat capacity anomaly decreases with increase in dopant concentration and then reaches a plateau. The concentration of dopant over which there will not be any decrease in the enthalpy and defect formation and the onset temperature of heat capacity anomaly is a function of the nature of the dopant. In the case of $\left(\mathrm{U}_{1-y} \mathrm{Gd}_{y}\right) \mathrm{O}_{2 \pm x}$ and $\left(\mathrm{U}_{1-y} \mathrm{La}_{y}\right) \mathrm{O}_{2 \pm x}$, it lies in the range of $15-20 \mathrm{~mol} \% \quad \mathrm{GdO}_{1.5}$ and $20-40 \mathrm{~mol} \% \quad \mathrm{LaO}_{1.5}$, respectively $[11,13]$.

The excess heat capacity $\left(\Delta C_{p}\right)$ due to the formation of Frenkel pair defects of oxygen is given by the following expression [10]:

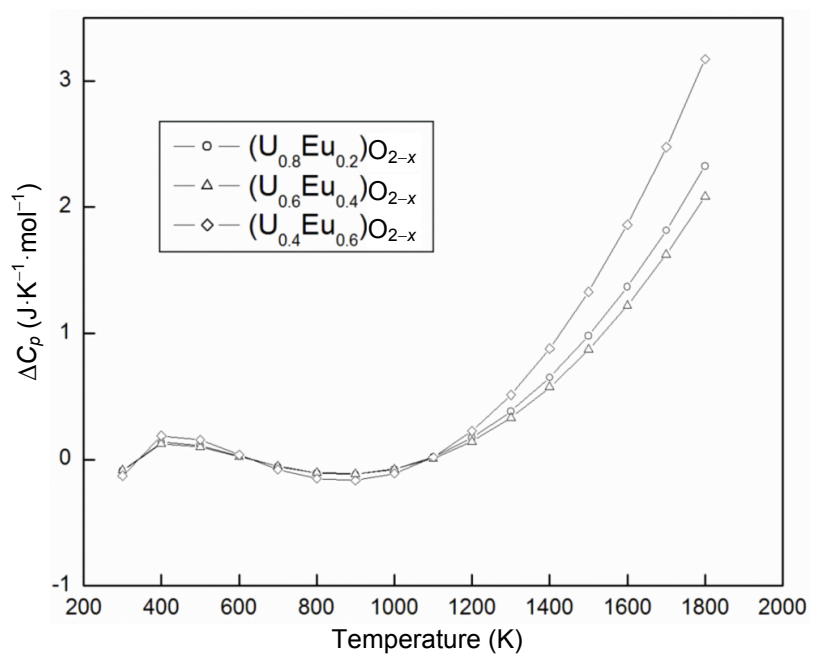

Fig. 5 Variation in the difference between the baseline and measured values of heat capacity $\left(\Delta C_{p}\right)$ with temperature of $\left(\mathrm{U}_{1-y} \mathrm{Eu}_{y}\right) \mathrm{O}_{2-x}(y=0.2,0.4,0.6)$.

$$
\Delta C_{p}=\frac{\left(\Delta H_{\mathrm{d}}\right)^{2}}{\sqrt{2} R T^{2}} \exp \left(\Delta S_{\mathrm{d}} / 2 R\right) \exp \left(-\Delta H_{\mathrm{d}} / 2 R T\right)
$$

where $R$ is the gas constant; $\Delta H_{\mathrm{d}}$ and $\Delta S_{\mathrm{d}}$ are the enthalpy and entropy for the formation of Frenkel pair defects of oxygen, respectively. The plot of $\ln \left(\Delta C_{p} T^{2}\right)$ against $1 / T$ is a straight line with a slope of $-\Delta H_{\mathrm{d}} / 2 R$. This plot for $\left(\mathrm{U}_{1-y} \mathrm{Eu}_{y}\right) \mathrm{O}_{2-x}(y=0.2,0.4,0.6)$ is shown in Fig. 6, and the enthalpy of defect formation computed from the slopes for all the solid solutions remains the same $(2.10 \pm 0.02 \mathrm{eV})$. The value of $\Delta H_{\mathrm{d}}$ reported by Matsui et al. [10] for $\left(\mathrm{U}_{1-y} \mathrm{Eu}_{y}\right) \mathrm{O}_{2}(y=0.09)$ is $1.7 \pm$ $0.2 \mathrm{eV}$. Therefore, it can be ascertained that there is no further decrease in the enthalpy of defect formation when the concentration of Eu increases from $y=0.09$ to $y=0.2$. The slight increase in the enthalpy of the defect formation observed from the present measurement may be due to errors in fitting. Therefore, the plateau region of the concentration of $\mathrm{EuO}_{1.5}$ over which there will not be any decrease in the enthalpy of the defect formation may be in the values between 9 and $20 \mathrm{~mol} \% \mathrm{EuO}_{1.5}$.

\section{Conclusions}

Heat capacity and enthalpy increment data pertaining $\left(\mathrm{U}_{1-y} \mathrm{Eu}_{y}\right) \mathrm{O}_{2-x}$ over the extensive range of composition $(20-60 \mathrm{~mol} \% \mathrm{Eu})$ are reported for the first time. The heat capacity of these solid solution decreases with the $\mathrm{Eu}$ content at all temperatures. An anomalous increase in the heat capacity is observed with the onset temperature around $950 \mathrm{~K}$ and is attributed to the

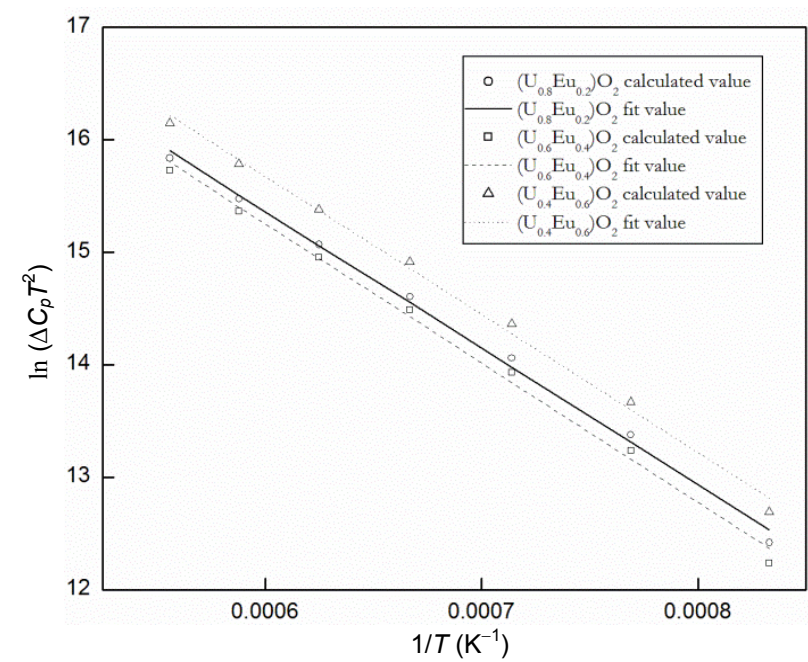

Fig. 6 Plot of $\ln \left(\Delta C_{p} T^{2}\right)$ vs. $1 / T$ in the temperature range 900-1800 K. 
formation oxygen Frenkel defect pairs. The enthalpy for the formation of these defects is computed from the excess heat capacity and is found to be nearly the same for all the solid solutions $(2.10 \pm 0.02 \mathrm{eV})$.

Open Access: This article is distributed under the terms of the Creative Commons Attribution License which permits any use, distribution, and reproduction in any medium, provided the original author(s) and the source are credited.

\section{References}

[1] Olander DR. Fundamental Aspects of Nuclear Reactor Fuel Elements. Virgina, USA: Springfield, 1985.

[2] Matzke Hj. Science of Advanced LMFBR Fuels. Amsterdam: Elsevier, 1986.

[3] IAEA-TECDOC-1168. Compilation and evaluation of fission yield nuclear data. 2000. Available at http:// www-pub.iaea.org/MTCD/Publications/PDF/te_1168_prn. pdf.

[4] Crouch EAC. Calculated independent yields in thermal neutron fission of sup233U, sup235U, sup239Pu, sup241Pu, and in fission of sup232Th, sup238U, and sup240Pu. Technical Report AERE-R-6056. 1969.

[5] Grossman LN, Lewis JE, Rooney DM. The system $\mathrm{UO}_{2}-\mathrm{Eu}_{2} \mathrm{O}_{3}$ at high temperatures. J Nucl Mater 1967, 21: 302-309.

[6] Fujino T, Ouchi K, Mozumi Y, et al. Composition and oxygen potential of cubic fluorite-type solid solution $\mathrm{Eu}_{y} \mathrm{U}_{1-y} \mathrm{O}_{2+x}(x \equiv 0)$ and rhombohedral $\mathrm{Eu}_{6} \mathrm{UO}_{12+x^{\prime}}\left(x^{\prime}<0\right)$. J Nucl Mater 1990, 174: 92-101.

[7] Haug H, Weigel F. Mischoxidsysteme von lanthaniden- und actinidenelementen: I. Röntgen-untersuchungen im system Uranoxid-Europiumoxid. J Nucl Mater 1963, 9: 355-359.

[8] Omichi T, Fukushima S, Maeda A, et al. On the relation between lattice parameters and $\mathrm{O} / \mathrm{M}$ ratio for uranium dioxide-trivalent rare earth oxide solid solution. $J \mathrm{Nucl}$ Mater 1981, 102: 40-46.

[9] Park K, Olander DR. Defect models for the oxygen potentials of gadolinium- and europium-doped urania. J Nucl Mater 1992, 187: 89-96.

[10] Matsui T, Kawase T, Naito K. Heat capacities and electrical conductivities of $\left(\mathrm{U}_{1-y} \mathrm{Eu}_{y}\right) \mathrm{O}_{2}(y=0.044$ and 0.090$)$ from 300 to 1550 K. J Nucl Mater 1992, 186: 254-258.
[11] Venkata Krishnan R, Mittal VK, Babu R, et al. Heat capacity measurements and XPS studies on uraniumlanthanum mixed oxides. J Alloys Compd 2011, 509: 3229-3237.

[12] Venkata Krishnan R, Babu R, Panneerselvam G, et al. Solubility studies and thermophysical properties of uranium-neodymium mixed oxides system. Ceram Int 2014, 40: 4395-4405.

[13] Venkata Krishnan R, Panneerselvam G, Manikandan P, et al. Heat capacity and thermal expansion of uraniumgadolinium mixed oxides. J Nucl Radiochem Sci 2009, 10: 19-26.

[14] Venkata Krishnan R, Nagarajan K, Vasudeva Rao PR. Heat capacity measurements on $\mathrm{BaThO}_{3}$ and $\mathrm{BaCeO}_{3} . J \mathrm{Nucl}$ Mater 2001, 299: 29-31.

[15] Venkata Krishnan R, Nagarajan K. Heat capacity measurements on uranium-cerium mixed oxides by differential scanning calorimetry. Thermochim Acta 2006, 440: 141-145.

[16] International Centre for Diffraction Data. Powder diffraction files (inorganic phases). Joint Committee on Powder Diffraction Data (JCPDS), ICDD card number 00-034-0392. 2013.

[17] Knacke O, Kubaschewski O, Hesselmann K. Thermochemical Properties on Inorganic Substances. Berlin: Springer, 1991.

[18] Fink JK. Thermophysical properties of uranium dioxide. J Nucl Mater 2000, 279: 1-18.

[19] Inaba H, Naito K, Oguma M. Heat capacity measurements of $\mathrm{U}_{1-y} \mathrm{Gd}_{y} \mathrm{O}_{2} \quad(0.00 \leqslant y \leqslant 0.142)$ from 310 to $1500 \mathrm{~K}$. J Nucl Mater 1987, 149: 341-348.

[20] Matsui T, Arita Y, Naito K. Heat capacity measurements of $\mathrm{U}_{1-y} \mathrm{La}_{y} \mathrm{O}_{2}(y=0.044,0.090,0.142)$ from 300 to $1500 \mathrm{~K}$. J Radioan Nucl Ch Ar 1990, 143: 149-156.

[21] Matsui T, Kawase T, Naito K. Heat capacities and electrical conductivities of $\left(\mathrm{U}_{1-y} \mathrm{Eu}_{\mathrm{y}}\right) \mathrm{O}_{2}(y=0.044$ and 0.090$)$ from 300 to 1500 K. J Nucl Mater 1992, 186: 254-258.

[22] Mills KC, Ponsford FH, Richardson MJ, et al. Heat capacity and enthalpy of $\mathrm{UO}_{2}$ and gadolinia-doped $\mathrm{UO}_{2}$. Thermochim Acta 1989, 139: 107-120.

[23] Arita Y, Matsui T, Hamada S. High temperature heat capacities of $\left(\mathrm{U}_{0.91} \mathrm{M}_{0.09}\right) \mathrm{O}_{2}$ (where $\mathrm{M}$ is $\mathrm{Pr}, \mathrm{Ce}, \mathrm{Zr}$ ) from 290 to 1410 K. Thermochim Acta 1995, 253: 1-9.

[24] Arita Y, Hamada H, Matsui T. High-temperature heat capacities and electrical conductivities of $\mathrm{UO}_{2}$ doped with simulated fission products for $2-10$ at $\%$ burnup. Thermochim Acta 1994, 247: 225-236.

[25] Inaba $\mathrm{H}$, Naito $\mathrm{K}$, Oguma $\mathrm{M}$, et al. Heat capacity measurement of gadalonia doped $(7.3 \mathrm{~mol} \%) \mathrm{UO}_{2}$ from 310-1370 K. J Nucl Mater 1986, 137: 176-178. 